удк 327(497.11:439)"1989/...";

$327(439) " 1989 / \ldots "$

Dr Jožef JUHAS

\title{
LOJALNOST ZAPADU I PRAGMATIZAM PREMA SRBIJI Politika Mađarske prema Srbiji nakon 1989.
}

\begin{abstract}
APSTRAKT: Studija analizira politiku Mađarske prema Srbiji od 1989. do početka druge decenije 21. veka. Odnose 90-ih godina autor kvalifikuje kao hladne i napete jer njihovu početnu atmosferu određuju razlike između političkih orijentacija dveju država: u Mađarskoj je 1989. započet proces "vesternizacije" i evroatlantske integracije, dok je u Srbiji režim Slobodana Miloševića vladao svom svojom snagom. Udaljavanju dve zemlje doprinosila je i politika mađarskih desničarskih vlada (npr. slučaj kalašnjikov). Nakon pada Miloševićevog režima nestao je jaz i time je stvorena nova osnova za izgrađivanje odnosa. Novi period već može biti kvalifikovan kao uspešan: mada između dve države postoje otvorena (većinom manjinska) pitanja, nema teških konflikata.
\end{abstract}

Ključne reči: Mađarska, Srbija, Jugoslavija, spoljna politika, međunarodni odnosi

Slomom bipolarnog svetskog poretka i evropskih socijalističkih sistema, mađarski i srpski narod jednako su doživeli radikalnu promenu političkih paradigmi: prošli su kroz promenu društveno-političkog sistema, štaviše, u slučaju srpstva, tome je dodata i "promena države". Ove okolnosti su doprinele tome da odnosi između Mađarske, koja je povratila svoj potpuni suverenitet, i Srbije, koja se ponovo državno konstituisala, dobiju novi kvalitet u toj meri da u mađarskoj savremenoj spoljnoj politici (ne računajući prisilne godine Drugog svetskog rata) zapravo samo od tog momenta možemo da govorimo o odnosima sa Srbijom u punom smislu reči. Naime, što se tiče ranijih epoha, to možemo da učinimo samo posredno. Do 1918. mađarska samostalna spoljna politika nije postojala, tako da su mađarski pogledi mogli da se pojave samo unutar spoljne politike Habzburške monarhije $i$ to u podređenom odnosu - ali $i$ to je bilo moguće samo nakon austrijsko-mađarske nagodbe 1867 . Počev od 1918. Mađarska je morala da se ravna prema Jugoslaviji u svim njenim oblicima - doduše, jugoslovenska država, u osnovi, u Mađarskoj je uvek smatrana srpskom (odnosno državom koja oličava prven- 
stveno srpske interese). U ovoj studiji želeo bih da prikažem kako je mađarska država prihvatila starog-novog suseda, kako je ocenila politiku Srbije prema Mađarskoj i dokle su stigle dve zemlje u razvijanju odnosa do početka druge decenije 21 . veka. Dakle, u žiži interesovanja nije odvijanje opštih mađarsko-srpskih odnosa, imajući u vidu da oni zavise od brojnih drugih činilaca, pre svega od međunarodnih uslova koji određuju radijus kretanja dve države, ali i od druge strane, tj. od namera i politike Srbije prema Mađarskoj. Ovom prilikom bih se fokusirao na mađarske poglede i stremljenja u vezi sa izgrađivanjem odnosa sa Srbijom, na jedan aspekt ove "tročlane igre" u kojoj učestvuju Mađarska, Srbija i međunarodna zajednica, tako da će u ovom radu biti reči o drugim aspektima samo u neophodnoj meri.

\section{Hladan odnos do 2000. godine}

Imajući u vidu osnovne principe, može se tvrditi da je mađarska spoljna politika nakon 1989. godine, bez obzira na promene vlada i međupartijska previranja, uvek bila sklona, a to čini i danas, razvijanju mađarsko-srpskih odnosa. ${ }^{1}$ To se uklapalo u trojni prioritetni sistem mađarske spoljne politike nakon promene društvenog uređenja, dakle u zbirne ciljeve evroatlantskih integracija, razvijanje dobrosusedskih odnosa i podržavanje mađarskih zajednica van granica Mađarske, ${ }^{2}$ uz izražavanje zainteresovanosti za jačanje bilateralnih odnosa. ${ }^{3}$

1 Mađarskom su od 1990. (od prvih slobodnih izbora) do 1994. kao i između 1998. i 2002. upravljale desničarske vlade, kao što je slučaj i sada (od 2010), pod vođsvom Mađarskog demokratskog foruma u prvom ciklusu, a u drugom i sadašnjem pod vođsvom Mađarskog građanskog saveza - Fidesa (Fidesz). U ostala tri ciklusa (1994-1998. i 2002-2010) zemljom su upravljale levičarske vlade sa Mađarskom socijalističkom partijom na čelu. Bez obzira na činjenicu da su između pojedinih vlada, odnosno partija uvek postojale veće ili manje razlike i da su ekstremni desničari (na primer u Partiji mađarske pravde i istine) i ranije imali borbenije stavove u vezi sa Srbijom, na mađarskoj političkoj sceni sve do pojave partije Jobik (Jobbik - „Pokret za bolju Mađarsku" - nova radikalna desničarska stranka u opoziciji) je vladao konsenzus u odnosu na osnovna pitanja mađarsko-srpskih odnosa. Na ovo pitanje ćemo se vratiti kasnije.

2 Danas oko 250.000 Mađara živi u Vojvodini (i oko 4.000 Srba u Mađarskoj).

3 Nova mađarska spoljnopolitička doktrina bila je sveobuhvatno izrađena relativno kasno (u suštini prvi pokušaj je predstavljala "Spoljnopolitička strategija" 2008), međutim, gore navedene osnovne principe u nekom vidu već od početka sadržali su pojedini programi vlade i više zaključaka parlamenta, npr. 11/1993. sz. Országgyülési Határozat a Magyar Köztársaság biztonságpolitikájának alapelveiről (Zaključci parlamenta o osnovnim principima bezbednosne politike Republike Mađarske pod brojem 11/1993, http://www.complex.hu/kzldat/093h0011.htm/093h0011.htm - 14/09/2012) i 94/1998. sz. Országgyülési Határozat a Magyar Köztársaság biztonság- és védelempolitikájának alapelveiről (Zaključci parlamenta Republike Mađarske o osnovnim principima bezbednosne i odbrambene politike, pod brojem 94/1998, http://www.mkih.hu/torvenyek/o98h0094/098h0094.htm, 05/03/2012). Već pomenuta "Spoljnopolitička 
Ovo osnovno polazište, međutim, nije bilo dovoljno za ponovno praktično izgrađivanje odnosa tako da on bude, makar gledajući samo iz mađarske perspektive, stvarno brz i pravolinijski. U Mađarskoj je 1989. započet proces rekapitalizacije i zemlja je krenula u pravcu parlamentarne demokratije i evroatlantske integracije, dok je u Srbiji režim Slobodana Miloševića vladao svom svojom snagom. Nije ni čudo što su se dve države (s jedne strane Mađarska i s druge strane Srbija, koja je nastupajući u mnogim aspektima kao samostalni akter, tada još uvek egzistirala kao država članica Jugoslavije) različito odnosile prema svim bitnim pitanjima međunarodnih odnosa, između ostalih i prema raspadu Jugoslavije i prema ratovima koji su pratili raspad zemlje. Početnu atmosferu mađarsko-srpskih odnosa u osnovi određuje diskrepancija. Udaljenost između dve zemlje, međutim, povećala je i politika tadašnje mađarske desničarske vlade pod vođstvom Jožefa Antala (Antall József). Najvažniji od ovih spornih koraka bio je takozvani "slučaj kalašnjikov". ${ }^{4}$ Kao što je poznato, Mađarska je oktobra 1990. prodala oružje Hrvatskoj, a nakon što je transakcija obelodanjena, u januaru 1991. najpre je negirala transporte, zatim je pokušala da ih bagatelizuje i da ih prikaže kao trgovinu bez političkih konotacija. O veličini transporta podaci su i dan danas protivrečni. Geza Jesenski (Jeszenszky Géza, ministar spoljnih poslova Antalove vlade) u svojim memoarima pominje istu količinu (10 hiljada automatskih pušaka), što je konačno i vlada priznala. ${ }^{5}$

strategija" (1012/2008. sz. Kormányhatározat a Magyar Köztársaság külkapcsolati stratégiájáról /Zaključci Vlade o strategiji spoljnih odnosa Mađarske pod brojem 1012/2008/, u Spoljnopolitičkom godišnjaku Mađarske 2008, http:// www.kulugyminiszterium.hu/NR/rdonlyres/057E8586-EFA9-428D-A8589A38285A130D/0/magyar kulugyi evkonyv 2008.pdf - 16/03/2012) potvrdila je kasnije ove principe, neposredno ukazujući na to da dobre odnose prema Srbiji Mađarska smatra svojim "strateškim interesom" i "dalekosežno podržava... postepeno ostvarivanje perspektive Srbije u integracijama" (ibid., p. 221). Stav Orbanove vlade, koja je došla na vlast 2010. u suštini je istovetan sa ovim: „Unutar procesa proširivanja u odnosu na zapadni Balkan, sa posebnom odlučnošću se zalažemo za što skorije pritupanje Srbije Evropskoj uniji, ujedno i za sveopštu primenu evropskih vrednosti i ostvarivanje uslova pristupanja Evropskoj uniji, kao i za održavanje mogućnosti pristupanja NATO-u." Magyar külpolitika az uniós elnökség után (Mađarska spoljna politika nakon mađarskog predsedavanja u Savetu EU, http://www.kulugyiintezet.hu/doc/files/kiadvanyok/egyeb/magyar kulpolitika az unios elnokseg utan.pdf - 17/03/2012) p. 21.

4 Lenkei Gábor (Gabor Lenkei), „A Kalasnyikov-ügy” (Slučaj Kalašnjikov), Skandalum, (ur. Gerő András /Andraš Gere/), T-Twins, Budapest, 1993, pp. 234-250; Szilágyi Imre (Imre Silađi), „A magyar külpolitika és a délszláv térség 1990 után” (Mađarska spoljna politika i južnoslovenski region nakon 1990), Külügyi Szemle, vol. III, no. 4, (1-2/2004), Budapest, 2004, 4-26, pp. 5-6 (Engleska verzija studije "Hungary and the Western Balkans since 1990", Foreign Policy Review / Budapest/, 1-2/2005, Budapest, 2005, pp. 184-200, http://www.kulugyiintezet. hu/pub/default.asp?y=2005\&t=8 $-14 / 09 / 2012$ )

5 Jeszenszky Géza, "Antall József, a külpolitikus” ( $O$ spoljnoj politici Jožefa Antala), Valóság, 12/2006, Budapest, 2006, 1-19, (cit. p. 12), http://www.valosagonline. hu/index.php?oldal=cikk\&cazon=290\&lap=11 - 16/03/2012). Jeszenszky Géza, „Jugoszlávia felbomlása és a magyar külpolitika" (Raspad Jugoslavije i mađarska 
Nasuprot tome, Martin Špegelj, tadašnji hrvatski ministar vojske, u jednom intervjuu tvrdi da im je isporučeno 24 hiljade automatskih pušaka, 2.100 mitraljeza, 400 ručnih protivoklopnih bacača (RPG) i 40 komada protivavionskih raketa Strela $2 \mathrm{M}$, zajedno sa municijom u vrednosti od 11 miliona dolara, i time je Mađarska postala jedan od glavnih izvora početnog hrvatskog uvoza oružja. ${ }^{6}$

Bez obzira na broj stvarno isporučenog oružja, može se konstatovati da je ova transakcija svakako bila pogrešna i u političkom smislu i u pogledu međunarodnog prava (pošto je obavljena pred izbijanje rata i iza leđa saveznih organa), ali je i negativno uticala na viđenje Mađarske u zapadnom svetu i u Srbiji, kao i na mađarsko-jugoslovenske odnose. Međutim, sa značajem mađarskog izvoza oružja ne treba preterivati, imajući u vidu da je on predstavljao malu stavku u odnosu na celokupni hrvatski uvoz (a kasnije je Mađarska stvarno poštovala embargo na prodaju oružja regionu). Ceo slučaj može se pre smatrati neiskustvom početničke vlade i njenim saplitanjem na spoljnopolitičkom planu nego razumnim strateškim korakom koji bi imao za cilj raspad Jugoslavije. ${ }^{7}$ Nije slučajno da se slučaj stišao za nekoliko nedelja - nakon što je vlada Mađarske priznala isporuke i izjavila je da nije želela i da neće da se meša u unutrašnja pitanja Jugoslavije ${ }^{8}$ - i nije naneo nepopravljive štete u mađarsko-srpskim odnosima.

spoljna politika). Külügyi Szem/e, vol. 10, no. 4, (4/2011), Budapest, 2011, 4279, (cit. str. 46), (engleska verzija studije „Hungary and the Break-Up of Yugoslavia", Hungarian Review, vol. II, no. 2 and 3, Budapest, 2011, http://hungarianreview.com/article/hungary and the break-up_of yugoslavia kao i http:// hungarianreview.com/article/hungary and the break up ofy ugoslavia part II $-11 / 09 / 2012$ )

6 Djordje Zelmanovic, "A Kalasnyikov-ügy, első kézből” (Slučaj Kalašnjikov, iz prve ruke), Népszabadság, 28. septembar 1995, Budapest, p. 6. Videti još Martin Špegelj, Sjećanja vojnika, Znanje, Zagreb, 2001 (http://www.scribd.com/ doc/37201893/Martin-Spegelj-Sjecanja-Vojnika - 12/03/2012), str. 104; Veljko Kadijević, Moje viđenje raspada - vojska bez države, Politika, Beograd, 1993 (http://hr.scribd.com/doc/117791683/Veljko-Kadijevic-Moje-Vidjenje-Raspada 13/11/2012), str. 26.

7 Članovi Antalove vlade ni nakon dvadeset godina ne tvrde to isto, ističu možda samo to da je transakcija doprinela poboljšanju ugleda Mađarske u hrvatskim krugovima. Śtaviše, ekstremna desnica je kasnije direktno optužila Antalovu vladu (kao i sve ostale vlade Mađarske devedesetih godina) da je propustila mogućnost teritorijalne revizije: „Istorijski proces, koji je započet '89. i trajao je do početka 2000-ih godina rezultirao je bar pola tuceta ozbiljnih istorijskih mogućnosti u kojima bi bilo koja od mađarskih vlada - dakle, Antalova, Hornova ili Orbanova - mogla da se umeša ili putem diplomatije ili putem snaga oružja jer je devetdesetih godina još postojala mađarska vojska. Ubedljivo tvrdim da u savezu sa Hrvatima mogli smo da povratimo teritorije koje su nam oduzete 1918. od strane Srba". (Raffay Ernő /Erne Rafai/, "Harmadik Trianon előtt" (Pred trećim Trianonom), Nagy Magyarország, 1/2009, http://tortenelemportal.hu/2009/08/ harmadik-trianon-elott/ - 13/09/2012)

8 "A Magyar Kormány nyilatkozata a magyar-jugoszláv viszony egyes kérdéseiről" (Izjava Vlade Mađarske o pojedinim pitanjima mađarsko-jugoslovenskih odnosa), Magyar Külpolitikai Évkönyv 1991 (Godišnjak mađarske spoljne politike 1991), KüM, Budapest, 1991, pp. 142-143. 
Mađarske odluke u vezi sa priznavanjem bivših jugoslovenskih republika takođe su dovele do konflikata u srpsko-mađarskim odnosima. Kao što je poznato, politika Mađarske u vezi sa Jugoslavijom u prvoj secesionističkoj fazi, za vreme otcepljenja država 1991-92. ravnala se prema stavovima velikih sila na Zapadu (uglavnom prema stavovima Nemačke), odnosno prema slovenačkim i hrvatskim očekivanjima. To se dobro vidi iz intervjua Jožefa Antala Der Standardu u broju od 3. jula 1991, (tu se premijer Mađarske zalaže za pravo na samoopredeljenje i suverenitet republika-članica i za konfederalizaciju Jugoslavije), odnosno iz mađarsko-poljske izjave premijera dveju država iz oktobra 1991, nakon isteka „Brionskog moratorijuma" o odlaganju slovenačke i hrvatske nezavisnosti za tri meseca (u izjavi dvojice premijera izneto je viđenje da se protiv Hrvatske odvija agresija koju treba zaustaviti slanjem međunarodnih mirovnih snaga). ${ }^{9}$ Nakon svega ovoga nije bilo iznenađenje kada je Mađarske samo dan nakon priznavanja članica Evropske zajednice, 16. januara 1992. priznala nezavisnot Slovenije i Hrvatske, a nešto malo kasnije i nezavisnost Bosne i Hercegovine, kao i Makedonije (FYROM). Istovremeno, slično stavovima međunarodne zajednice, nije pokazala spremnost na priznavanje secesija Srba u Hrvatskoj i Bosni (Republike Srpske Krajine i Republike Srpske u Bosni), čak ni na to da prizna zahtev srpsko-crnogorske „Male Jugoslavije” (SRJ), proglašene 27. aprila 1992. o jednostranom pravnom nasledstvu nekadašnje (Titove) Socijalističke Federativne Republike Jugoslavije (SFRJ). Iz ovih razloga (ravnajući se takođe prema tadašnjoj politici sankcionisanja UN-a), bez obzira na održavanje kontinuiteta diplomatskih odnosa sa jednom i drugom Jugoslavijom na niskom nivou, Budimpešta je ove odnose podigla na razinu ambasadora tek 15. avgusta 1996, nakon okončanja rata u Bosni Dejtonskim sporazumom (da bi zbog NATObombardovanja 1999. ti odnosi bili ponovo vraćeni na nivo otpravnika poslova).

Mađarski i srpski stavovi su bili različiti i za vreme drugog secesionističkog ciklusa. U tom periodu 4. februara 2003. Savezna Republika Jugoslavija preuređena je u Državnu zajednicu Srbije i Crne Gore, koja se raspala u periodu između 2006. i 2008. Mađarsko priznanje nezavisnosti Crne Gore, koja je deklarisana 3. juna 2006, nije izazvalo mađarsko-srpski bilateralni konflikt (pošto se otcepljenje Crne Gore odvijalo putem sporazuma, na osnovu scenarija koji je prihvatila i Srbija), međutim, mađarsko priznanje Republike Kosovo, koja je proglašena 17. februara 2008, indukovalo je otvorene rasprave. Prema mađarskom stavu, imajući u vidu realnost i volju zapadnih velikih sila, omogućavanje nezavisnosti Kosova je neophodno; ali uz to proces osamostaljivanja treba usmeriti na način koji bi za Srbiju

9 "Magyar-lengyel kormányfői nyilatkozat 08/10/1991" (Izjava premijera Mađarske i Poljske 08/10/1991), Magyar Külpolitikai Évkönyv 1991 (Godišnjak mađarske spoljne politike 1991), Küm, Budapest, 1991, p. 311. 
bio što manje bolan, ne bi izazvao nekonstrolisanu regionalnu krizu (na zapadnom Balkanu) i ne bi doveo do međuetničkih incidenata u Vojvodini. Na osnovu ovoga, Mađarska je priznala Republiku Kosovo, ali u nedostatku zajedničkog stava unutar Evropske unije (čemu se mađarska vlada u suštini nadala), to se dogodilo 19. marta, nakon čekanja i koordinisanja u periodu od samo mesec dana, kada je već Srbija prevazišla najintenzivnije emocionalne reakcije zbog secesije Kosova. Po mom mišljenju, mađarske računice su se pokazale ispravnima, pošto je, uz "unapred ukalkulisane" diplomatske proteste, Srbija primila k znanju ove događaje i najkasnije do novembra 2008, do vremena posete tadašnjeg premijera Mađarske Ferenca Đurčanja (Gyurcsány Ferenc) Beogradu, bilateralni odnosi su već prevazišli ovo privremeno diplomatsko zahlađenje. ${ }^{10}$ Ipak, neosporno je da su mađarske reakcije na državna otcepljenja (koja mogu biti ispravna iz mađarskog ugla, ali su u suprotnosti sa srpskim stavovima) u periodu 1991-92. i 2008, na duže ili kraće staze, uvek su otežavale uslove izgrađivanja bilateralnih veza. ${ }^{11}$

Ratovi (na teritoriji bivše Jugoslavije) u periodu između 1991. i 1995. kao i 1998. i 1999. Mađarsku i Srbiju takođe su postavili na suprotne položaje. Ponavljajući ratovi su u Mađarskoj izazvali bezbednosno političke rizike i ekonomske gubitke, a Mađarima u Jugoslaviji su naneli direktne udarce. U Mađarsku je stiglo oko 40-50 hiljada izbeglica, broj žrtava ratova mađarske nacionalnosti iznosi više stotina, a ekonomski gubitak Mađarske je procenjen na oko tri milijarde američkih dolara. ${ }^{12}$ Mađarsko-srpsku udaljenost povećala je i činjenica da je u međunarodnim raspravama povodom jugoslovenskih ratova Budimpešta brzo prisvojila zapadna shvatanja da nije reč o konfliktu u vidu građanskog rata koji se može smatrati unutrašnjim pitanjem, nego je reč o borbi između agresora i žrtava i da u toj borbi - bez obzira na to što nije uvek srpska politika bila kriva - agresor je u osnovi srpska strana. U ovom duhu Mađarska je prihvatila i primenila međunarodne sankcije protiv SR Jugoslavije (počev od ekonomskih sankcija, koje je uveo UN maja 1992. do martovsko-junskog rata u vidu vazdušnih napada NATO-a 1999), čak u pojedinim periodima

$10 \mathrm{U}$ to vreme pored Kancelarije premijera delovalo je spoljnopolitičko savetodavno telo (Savet za spoljnu i bezbednosnu politiku) i kao član tog tela i sam sam uviđao da u ovom pitanju ne postoji zaista dobro rešenje, pa sam iz mađarskog ugla politiku "odloženog priznanja" smatrao sam najmanje lošim izborom.

11 Ovaj problem ukazuje na to da je bilo inkonzistencije i improvizacije i u mađarskim koracima. Doduše, mađarska spoljna politika trudila se da u izoštrenim kriznim situacijama pronađe rešenja koja su prihvatljiva i za Srbiju, ona nije mogla uvek da stvori sklad između različitih relacija sa zapadnim Balkanom (između odnosa sa Srbijom, Hrvatskom, Bosnom itd.).

12 Szilágyi Imre, "Magyarország és Szerbia viszonya a rendszerváltás óta eltelt időszakban" (Odnosi Mađarske i Srbije u periodu nakon promene društvenog sistema), Külügyi Szemle, vol. 10, no. 4 (4/2011), Budapest, 2011, pp. 80-94. (cit. str. 82), http://www.kulugyiintezet.hu/pub/default.asp?y=2011\&t=3 15/09/2012. 
(kao nestalni član Saveta bezbednosti Ujedinjenih nacija 1992-93, a od 1999. kao član NATO-a) neposredno je učestvovala u formiranju i donošenju ovih sankcija. ${ }^{13}$

Ove odluke bile su praćene teškim dilemama i uopšte nisu bile bez rizika. Naročito je bilo tako 1999, kada je NATO-bombardovanje Srbije stvorilo izuzetno tešku situaciju. Tada je Mađarska i sama postala učesnik borbenih dejstava (doduše samo posredno, putem prepuštanja vazdušnog prostora i aerodroma) i to kao jedini član NATO-a čija nacionalna manjina živi u Srbiji. Ove dileme su očigledno odigrale ulogu u tome da je Mađarska u tom periodu imala dvostruku politiku prema Srbiji: nastojala da drži otvorena vrata prema Srbiji, dok se istovremeno (u nastojanju uključivanja u zapadne integrativne saveze) trudila da bude lojalna politici Zapada. Ali, sve vlade su uviđale (makar zbog Mađara u Vojvodini) da se prema Miloševićevim vlastima treba odnositi na pragmatičan način. Budimpešta je iz ovih razloga nastojala i za vreme ratova i embarga UN-a da u najmanjoj mogućoj meri (samo koliko su to zahtevale međunarodne obaveze) ograničava međudržavne kontakte i ekonomske odnose, trudeći se da sve to premosti održavanjem civilnih kontakata i humanitarnom otvorenošću (prihvatanjem izbeglica - ne samo Mađara - i tolerisanjem malograničnog šverca u manjem obimu), kao i podržavanjem opozicionih struja, što pokazuje i "Segedinski proces", ugrađen u Pakt stabilnosti (ovaj program, koji je bio u službi razvoja demokratskih procesa i razvoja lokalnih samouprava zapadnog Balkana, Mađarska je između 1999. i 2009. podržala sa oko četiri miliona evra). ${ }^{14}$ Gledajući u celini, ipak nije čudo što mađarsko-srpske odnose 90-ih godina (tačnije, odnose Mađarske i SR Jugoslavije - da bismo se ravnali prema upotrebi naziva država u tim godinama),15 ne računajući neka "talasanja", u suštini za sve to vreme moramo da kvalifikujemo kao hladne, napete i na niskom nivou - za razliku od dobrih mađarsko-jugoslovenskih odnosa 80-ih godina.

13 O mađarskoj aktivnosti u svojstvu nestalnog člana u SB UN povodom jugoslovenskog pitanja videti još: Erdős André (Andre Erdeš), „Adalékok a magyar diplomácia történetéhez a rendszerváltozás korában" (Dodaci istoriji mađarske diplomatije za vreme promene društvenog sistema), Külügyi Szemle, vol. VIII, no. 1 (1/2009), Budapest, 2009, pp. 186-211, http://www.kulugyiintezet.hu/pub/ default.asp? $y=2009 \& t=3-14 / 09 / 2012$.

14 Petheő Ádám (Adam Pete), "Magyarország és a Balkán” (Mađarska i Balkan), Budapest, 2009, http://mta.hu/fileadmin/2009/03/PetheoBalkan.pdf - 13/09/2012 (cit. str. 2.).

15 Ova dva odnosa su u praktičnom smislu mogla biti sasvim izjednačena, naime odnosi Mađarske i Savezne Republike Jugoslavije potpuno su se ostvarivali kroz mađarsko-srpske odnose. Ovo se dobro može ilustrovati činjenicom da je Mađarska neposredno predstavništvo u Podgorici, u glavnom gradu Crne Gore, otvorila tek 17. novembra 2005, ali ni tada ne kao samostalnu kancelariju nego kao izmešteno odeljenje Ambasade Mađarske u Beogradu, akreditovano u Državnoj zajednici Srbije i Crne Gore. 


\section{Novi period odnosa od 2000.}

Nakon pada Miloševićevog režima oktobra 2000. nestalo je nesaglasja između političkih orijentacija i pravaca razvoja dveju država i time je stvorena nova osnova za izgrađivanje odnosa. Budimpešta je pozdravila preokret, Demokratska opozicija Srbije (DOS) odnosila se prema Mađarskoj mnogo prijateljskije nego režim Slobodana Miloševića, ${ }^{16}$ čemu su doprineli i mnogobrojni raniji (iz perioda pre 2000) dobri lični kontakti mađarskih političara sa značajnim delom čelnika DOS-a. Savez vojvođanskih Mađara (SVM), kao član DOS-a, postao je član nove vlade u Beogradu. Tako su promene u Beogradu olakšale Mađarskoj da premosti relativno pasivnu (opreznu, zapadnjačku, slaboinicijativnu) politiku ${ }^{17}$ perioda između 1991. i 1999. (od slučaja "kalašnjikov" do "Segedinskog procesa"), da poveća svoju posvećenost odnosima sa Srbijom i da započne sa iznošenjem argumenata o opravdanosti međunarodne rehabilitacije Srbije i njenog prijema u Evropsku uniju (naročito nakon prijema Mađarske u Evropsku uniju 2004).

Krajem 2000. godine, dakle, u istoriji mađarsko-srpskih odnosa zaista je započet novi period, koji u suštini već može biti kvalifikovan kao uspešan. Mada je za vremene Koštuničinih vlada između

16 Prema mađarskim ocenama do 2000. i Srbija je imala dvostruku politiku prema Mađarskoj jer je "nastojala da drži otvorena vrata prema Zapadu /.../ dok se istovremeno iz propagandističkih razloga trudila /.../ da prikaže Mađarsku kao neprijatelja Jugoslavije”. (Jeszenszky Géza, „Antall, a külpolitikus” /Spoljna politika Antala/, Magyar Szemle, vol. XXI, no. 5-6. (5-6/2012), Budapest, 2012, http:// www.magyarszemle.hu/cikk/antall a kulpolitikus 2 -2012.11.23).

17 Ovakvi odnosi u celini nisu bili karakteristični samo za politiku prema Srbima nego za sve balkanske odnose. Mada je nakon promene društvenog sistema mađarska spoljna politika Balkan uvek stavljala na otmeno mesto u prioritetima, u praksi to često nije bilo više od retorike (i danas je to tako). Iza toga stoji više razloga, kao što su na primer ograničenost kapaciteta (Mađarska nije bila sposobna na takav učinak u izvozu kapitala i u donacijama koji bi u ekonomskom smislu mogao da obezbedi jednu stvarno ambicioznu ulogu), specifična uloga Mađara u Vojvodini i u Transilvaniji (Budimpešta nije želela da oni budu eventualni objekti odmazde Bukurešta ili Beograda zbog za njih neprihvatljivih koraka) i umerena zainteresovanost balkanskih suseda (uglavnom je mađarska država bila ta koja je pokazala veću zainteresovanost za izgrađivanje međusobnih veza). Opreznosti odnosa doprinela je i činjenica da je u godinama nakon promene društvenog sistema mađarske stavove u odnosu na prostore jugoistočne Evrope karakterisala dosta jaka ambivalencija. Mada je Budimpešta bila zainteresovana za razvijanje odnosa na Balkanu, istovremeno se trudila da se distancira od celog prostora jugoistočne Evrope. Mađarska je, naime, želela što skorije članstvo u centralnim institucijama evropskih integracija, u Evropskoj uniji i NATO-u, pa je svakako želela da se pokaže kao zapadnjačka država (kao deo centralne Evrope, koja pripada Zapadu) i nije želela da je na Zapadu bilo ko posmatra kao deo jednog zaostalog kriznog područja. Više o tome u delu Oskara Fizeša: Füzes Oszkár, "The Main Elements of Hungary's Balkan Strategy", The Analyst, vol. 3, no. 4 (4/2007), Budapest, 2007, pp. 33-48, http://www.ceeol.com/aspx/issuedetails. aspx?issueid $=6 \mathrm{~b} 92 \mathrm{~d} 3 \mathrm{ad}-\mathrm{d} 608-420 \mathrm{f}-88 \mathrm{c} 2-42874791660 \mathrm{f} \& \mathrm{articleId}=01407 \mathrm{ee} 2-$ 6394-454e-80f7-6dadbb408742 - 2011.03.30. 
2004. i 2008. pristup bio malo oprezniji, to nije značilo i promenu smera, a nakon srpskih izbora 2008. ponovo je intenzivirana politička aktivnost. O novim trendovima rečito govori i to da su, počevši sa posetom tadašnjeg premijera Zorana Đinđića Budimpešti u aprilu 2001, ponovo pokrenuti susreti državnog vrha dve zemlje, koji su kasnije postali češći. Narednih godina sklopljeni su bilateralni sporazumi, i time su prošireni pravni i institucionalni okviri međudržavnih odnosa. Takvi su bili, na primer, i sporazum o slobodnoj trgovini, koji je stupio na snagu 1. jula 2002, sporazum o zaštiti manjina, potpisan 21. oktobra 2003. prilikom posete premijera Zorana Zivkovića Budimpešti, sporazum o viznom režimu sa početkom primene od 1. novembra 2003, kao i sporazum o kulturnoj saradnji, potpisan 13. maja 2006. Mešovita komisija za ekonomsku saradnju dve vlade održala je prvu sednicu 9. maja 2006, a 21. maja 2010. ministri odbrane dve zemlje postigli su sporazum o saradnji u ovoj oblasti.

Pored bilateralne saradnje Mađarska je na forumima Evropske unije redovno nastupala u cilju interesa približavanja Srbije Evropskoj uniji. Lobiranje Mađarske, kao jedinog "šengenskog suseda" Srbije, odigralo je veliku ulogu u odobravanju bezviznog režima Srbiji od 19. decembra 2009, a to što joj nije odobren status kandidata Evropske unije u prvoj polovini 2011. za vreme mađarskog predsedavanja Evropskom unijom nije zavisilo od mađarske strane, pogotovo što je to bio jedan od ciljeva njenog predsedavanja - imajući u vidu da se približavanje zapadnog Balkana integracijama smatralo jednim od prioriteta. ${ }^{18}$ Može se reći i to da je između 2001. i 2008. godine relativno dinamično povećavana bilateralna trgovina (najviše mađarski izvoz), a povećan je i obim mađarskih ulaganja: pre svega posredstvom MOL-a, OTP-a i "Betonuta” u Srbiji je formirano skoro 500 preduzeća u mađarskom (ili mešovitom) vlasništvu u vrednosti od 350 miliona dolara. ${ }^{19}$ Formiranje organizacija u službi razvoja neposrednih odnosa privrede i preduzetnika (Mađarsko-srpski ekonomski savet, Mađarsko-srpska trgovinska i industrijska komora ${ }^{20}$ bilo je u službi jačanja privredne kooperacije. Pored toga Mađarska je, shodno njenim snagama, učestvovala u projektima Zapada za podršku Srbiji: na primer u mađarskom programu NEFE (međunarodna razvojna saradnja) Srbija je postala jedna od istaknutih partnerskih zemalja (odnosno SRJ, a kasnije Srbija i Crna Gora). Ekonomske odnose

18 Szilágyi Imre, „Mgyarország és Szerbia viszonya a rendszerváltás óta eltelt időszakban", str. 87.

19 M. Császár Zsuzsa (Žuža, Časar M.), „Magyarország gazdasági, politikai és kulturális kapcsolatai a Balkán egyes államaival a 21. század elején" (Ekonomski, politički i kulturni odnosi Mađarske sa nekim balkanskim državama početkom 21. veka), Modern Geográfia, 1/2010, Budapest, 2010, pp. 1-23, (cit. str. 14), http://www.moderngeografia.eu/wp-content/uploads/2012/02/csaszar zsuzsa 20101 .pdf $-11 / 01 / 2013$. U tom periodu je vrednost srpskih ulaganja u Mađarskoj bila oko 50 miliona dolara.

Sajt ovog poslednjeg je: http://www.mszkik.hu 
između dve države dobro ilustruju sledeće brojke (koje se odnose na srpske spoljnotrgovinske podatke i iskazene su u US-dolarima). ${ }^{21}$

\begin{tabular}{|c|c|c|c|c|}
\hline Godina & Izvoz & Uvoz & Ukupno & Deficit \\
\hline 1995. & 19,5 & 58,9 & 78,4 & 39,4 \\
\hline 1996. & 29,6 & 125,9 & 155,5 & 96,3 \\
\hline 1997. & 59,7 & 124,7 & 184,4 & 65,0 \\
\hline 1998. & 54,2 & 112,6 & 166,8 & 58,4 \\
\hline 1999. & 28,1 & 94,0 & 122,1 & 65,9 \\
\hline 2000. & 52,8 & 111,6 & 164,4 & 58,8 \\
\hline 2001. & 59,2 & 175,7 & 234,9 & 116,5 \\
\hline 2002. & 73,5 & 247,7 & 321,2 & 174,2 \\
\hline 2003. & 75,7 & 261,3 & 337,0 & 185,6 \\
\hline 2004. & 123,3 & 320,7 & 444,0 & 197,4 \\
\hline 2005. & 132,9 & 267,4 & 400,3 & 134,5 \\
\hline 2006. & 181,9 & 427,6 & 609,5 & 243,7 \\
\hline 2007. & 247,5 & 707,0 & 955,4 & 460,4 \\
\hline 2008. & 327,8 & 799,7 & $1.127,5$ & 471,9 \\
\hline 2009. & 262,8 & 465,2 & 728,0 & 202,4 \\
\hline $\begin{array}{c}\text { Januar-oktobar } \\
2010 .\end{array}$ & 248,1 & 585,4 & 833,5 & 337,3 \\
\hline
\end{tabular}

U godinama nakon 2000. dinamičan razvoj saradnje neosporno ukazuje na postojanje političke volje za izgradnju odnosa sa obe strane, i ona nije bila kočena protivljenjem velikih sila. Mada su mađarski analitičari smatrali da su za srpsku spoljnu politiku i nakon 2000. godine "bili karakteristični neusklađeni ciljevi i sredstva", oni su istakli da i u ovom „usmeravanju pravca spoljne politike može da se otkrije jedan istaknuti prioritet: pridruživanje Evropskoj uniji".22

21 Nevenka Jeftić-Šarčević, "Geopolitical correlation between Serbia and Hungary The importance of connections between the Danube and the Black Sea regions", Mediterrán és Balkán Fórum, vol. VI, no. 1 (15/2012), Budapest, 2012, pp. 20-19 (cit. str. 27).

22 Orosz Anna (Ana Oros), „Szerbia külpolitikája a koszovói háború lezárulásától a tartomány függetlenedéséig" (Spoljna politika Srbije od završetka kosovskog rata do nezavisnosti pokrajine), Grotius, Budapest, 2008 (http://www.grotius.hu/publ/displ.asp?id=FKRUIW -11/09/2012.), pp. 1 i 18 . O prioritetima i raspravama savremene srpske spoljne politike videti: Edita Stojić-Karanović i Slobodan Janković (ur.), Elementi strategije spoljne politike Srbije, Institut za međunarodnu politiku i privredu, Beograd, 2008, str. 387. (http://www.scribd. com/doc/16918590/Elementi-Strategije-Spoljne-Politike-Srbije - 12/03/2012); Dragan Đukanović i Ivona Lađevac, "Prioriteti špoljnopolitičke strategije Republike Srbije", Međunarodni problemi, vol. LXI, no. 3 (3/2009), Beograd, 2009, str. 343-364. (http://scindeks-clanci.nb.rs/data/pdf/0025-8555/2009/0025- 
Kao neposredan uzrok nedoslednosti i oklevanja oni su označili podeljenost srpske političke klase, kao i činjenicu da proces promene elite još nije završen, tako da „još nije formiran stabilan rukovodeći sloj, čiji ciljevi i legitimitet bi se ogledali u približavanju Evropskoj uniji ..../zato bi - J. J./ ... vlast koja je polovično reformska, u svakom momentu mogla biti zamenjena (i na demokratskim izborima!) sa nacionalističkom opozicijom". ${ }^{23}$ Perspektive mađarsko-srpskih odnosa i značaj Mađarske u srpskim spoljnim poslovima - za koje su karakteristične „političke klackalice” (zbog manevrisanja između Zapada i Rusije, prema mađarskim ocenama) - mađarski analitičari i učesnici spoljne politike posmatrali su zato samo sa "umerenim optimizmom". Istovremeno, imali su na umu i to da će namere Srbije o pridruživanju Evropskoj uniji u njenim spoljnopolitičkim konceptima povećati značaj Mađarske. Prema njihovom viđenju, za Srbiju je važan mađarski komunikacioni i saobraćajni tranzit, a u Beogradu su verovatno svesni činjenice da "na osnovu susedstva i zbog mađarske manjine u Vojvodini, Mađarska je zainteresovana za pridruživanje Srbije Evropskoj uniji (mnogo više u odnosu na prosek u Evropskoj uniji!)"24 Značaj odnosa sa Mađarskom u srpskoj spoljnoj politici može da poveća i zajednički interes u pograničnim razvojnim programima i u Dunavskoj strategiji Evropske unije, na šta se pozivaju i srpski autori. ${ }^{25}$

Odnosi nisu bili bez konflikata ni nakon oktobra 2000. godine, kao što smo već povodom Kosova pomenuli. Interesantno je da je u ovom periodu čak došlo i do nekoliko konflikta u manjinskoj politici, do takozvanog slučaja napada na Mađare, ${ }^{26}$ do rasprave oko zakona o restituciji i obeštećenju ${ }^{27}$ i do rasprave oko parlamentarnog

85550903343D.pdf - 12/03/ 2012)

23 Füzes Oszkár, "Nyugat, Balkán, Nyugat-Balkán” (Zapad, Balkan, Zapadni Balkan), Európai Tükör, 5/2006, Budapest, 2006, pp. 26-40 (cit. str. 32), http:// www. kulugyminiszterium.hu/NR/rdonlyres/1885616D-5B88-4C0E-9298C97E332D9E5A/0/et_2006_05.pdf - 11/09/ 2012.

24 Isto, str. 35-36.

25 Nevenka Jeftić-Šarčević, "Geopolitical correlation between Serbia and Hungary - The importance of connections between the Danube and the Black Sea regions"; Edita Stojić-Karanović, "A határokon átívelő együttműködés jelentősége a vajdasági kisrégiók fenntartható fejlődésében" (Značaj prekogranične saradnje u održivom razvoju vojvođanskih malih regija), http://www.balkancenter.hu/pdf/ stijc.pdf - 08/09/2012.

26 Incidenti protiv Mađara u Vojvodini, poznati kao "napadi na Mađare” postali su učestali u periodu 2003-2004, i to u toj meri da je mađarska strana bila primorana da pitanje iznese na međunarodni forum: Evropski parlament na sednici od 16. septembra 2004. usvojio je zaključak u kojem je pozvao Beograd da spreči ove incidente.

27 Skupština Srbije je 26. septembra 2011. usvojila Zakon o restituciji u formi koja bi (prema mađarskim procenama) na osnovu principa kolektivne krivice isključila značajan deo vojvođanskih Mađara iz procesa reprivatizacije i obeštećenja. Protiv ovakve formulacije zakona protestovale su mađarske partije u Vojvodini i Budimpešta je predočila da će na sednici Evropskog saveta 9. decembra uložiti 
predstavljanja srpske manjine u Mađarskoj. 28 Međutim, bez obzira na rasprave, pažnju zaslužuje ozbiljan napredak u manjinskoj politici (u Mađarskoj nakon 1989. i u Srbiji nakon 2000) i to u tolikoj meri da za današnje pravne okvire zaštite manjina možemo da kažemo da oni prevazilaze evropski prosek (mada oni nisu savršseni i očigledne su razlike između stanja de jure i stanja de facto). Štaviše, dogodio se napredak u uzajamno bolnoj istorijskoj temi: predsednici država Laslo Šojom (Sólyom László) i Boris Tadić u oktobru 2009. u Budimpšti postigli su dogovor o osnivanju Srpsko-mađarske akademijske mešovite komisije za otkrivanje istine o konfliktima u Drugom svetskom ratu. ${ }^{29}$ A na kraju, što se sadašnjeg stanja i "uskog preseka" mađarsko-srpskih odnosa tiče, ne bih istakao odsustvo konflikata (bez obzira na postojanje izvesnih otvorenih pitanja), nego bih radije usmerio pažnju na relativno nizak intenzitet, imajući u vidu da odnosi ni dan danas ne dostižu željeni i mogući nivo. Na primer, ulaganje od 400 miliona dolara u prvi mah zvuči lepo, međutim u stvarnosti to nije prevelika suma. Na "listu nedostataka" možemo da stavimo i to da dve države međusobno nisu pokrenule pitanje osnivanja kulturnih centara, mada bi to bilo važno u pogledu međusobnog razumevanja dva susedna naroda. ${ }^{30}$ Sudeći prema ovome, mađarsko-srpsku saradnju i danas više karakterišu neiskorišćene nego realizovane mogućnosti - nadalje, od finansijke svetske krize 2008. godine međusobna pažnja je umanjena. Naravno, zna se da su za smanjivanje "liste nedostakata" potrebne ne male pare, a trenutno nijedna država ne može da dozvoli sebi da razmišlja o velikodušnim investicionim poreskim olakšicama, o finansiranju novih projekata i institucija. Zato je od izuzetne važnosti da kao dobre možemo da označimo bar političke osnove razvijanja odnosa: između dve države još postoje otvorena pitanja, ali nema teških konflikata, a na razini vlada postoji međusobna spremnost na saradnju i dobri su i međunarodni uslovi.

Sumiranjući savremene mađarsko-srpske odnose može se reći da ova istorija odnosa, bez obzira na svu njenu problematičnost, nije samo istorija konflikata ni na nivou država ni na nivou svakodnevnih kontakata stanovništva koje živi zajedno. Mada sa izvesnom dozom optimizma, ipak možemo mirno da formulišemo iskustvo o tome da u slučaju postojanja međusobne političke volje država za saradnju i

veto na status kandidata Srbije. Na kraju, postignut je kompromis, čime su sporni paragrafi Zakona o restituciji ostali važeći, međutim Zakonom o rehabilitaciji od 5. decembra oni su konkretizovani: prema ovome, iz procesa obeštećenja mogu da budu isključeni samo ratni zločinci. Mađarska je nakon ovoga povukla pretnje o vetu.

28 U Mađarskoj nažalost sve do danas nije rešeno parlamentarno predstavljanje manjina. Zbog toga npr. Srbija smatra da i položaj Srba u Mađarskoj statusno gori nego položaj Mađara u Srbiji.

29 Sajt mađarske sekcije komisije: http://www.magyarszerbmult.hu

30 U ovom kontekstu obećavajuća je izjava zamenika premijera Mađarske Tibora Navračiča (Navracsics Tibor) na beogradskom sajmu knjiga u oktobru 2012. da Budimpešta planira osnivanje "Mađarske kuće" u Beogradu. 
postojanja potrebnog minimuma etničke tolerancije kod vladajućih elita, ovo susedstvo može da postane korisna simbioza za obe strane. Može da bude simbioza koja je dobro prepoznatljiva na osnovu perioda saradnje između dve države i multikulturalnosti Vojvodine - ili pak na osnovu životnog dela istaknutih ličnosti sa dvojnim vezama, na koje obe strane mogu da budu ponosne (braća Vujičić, Danilo Kiš itd.).

Povodom mađarsko-srpskih odnosa u Budimpešti i dan danas postoje borbeniji stavovi. Poznat je stav Jobika da bi, za uzvrat za pridruživanje Srbije Evropskoj uniji, Mađarska trebalo da zahteva od Srbije istorijsko izvinjenje i teritorijalnu autonomiju na etničkom principu. ${ }^{31} \mathrm{U}$ vezi s tim možemo reći da nema potrebe za promenom strategije: uspešnost ostvarivanja interesa mađarske države i zaštitu manjinskih prava mađarske zajednice u Vojvodini dugoročno može da garantuje samo politika međusobnog partnerstva. Jer "došlo je vreme kada bi obe strane trebalo da prepoznaju da - nasuprot dominantnim trendovima u devetnaestom i dvadesetom veku, dakle nasuprot nacionalističkoj eri međusobnih rivalizacija tokom izgrađivanja država i nacija - Mađari i Srbi danas mogu da imaju jaču interesnu zajednicu sa zajedničkim ciljevima od sukoba interesa, s obzirom na to da je samo saradnja ta koja može da pruži odgovore globalnim izazovima i iskoristi prednosti evropskih integracija /.../ uslov tome, naravno, jeste da dve države budu sposobne da naprave iskorak iz stalnog zahteva za polaganje računa zbog međusobnih istorijskih rana i da budu spremne na rešavanje otvorenih manjinskih pitanja, pošto su ovo problemi koji u savremeno doba emocionalno najviše opterećuju međusobne odnose."32 I da dodam: mađarsko javno mnjenje smatra da u onome u čemu su uspeli Francuzi i Nemci, mogli bi da budu uspešni i Mađari i Srbi - makar na duže staze. Zašto ne bi bilo moguće da mađarsko-srpski odnosi u krajnjem bilansu igara prevlasti dostignu nulti nivo (kada dobitak pobednika izgubi onaj drugi, što je bio slučaj tokom istorije već toliko mnogo puta) i zašto ne bismo mogli da budemo jedan od pozitivnih primera dobrosusedskog suživota unutar modernih evropskih integracija?

31 Već smo ukazali na to (1. fusnota) da su u ekstremno desničarskoj subkulturi i ranije bila formulisana militantna mišljenja, međutim ona politički nisu bila značajna sve do ulaska Jobika u parlament (2010). Od tada, međutim, i na parlamentarnoj sceni se glasno čuju stvavovi sa ciljem rušenja ranijih konsenzusa - mada "u slučaju odgovarajućih uslova" ni Jobik se ne protivi proširivanju mađarsko-srpskih odnosa („Feltételekkel tudjuk támogatni Szerbia EU- csatlakozását" /Pridruživanje Srbije Evropskoj uniji možemo da podržimo pod određenim uslovima/, http:// www.mrm.rs/aktualis/501-feltetelekkel-tudjuk-tamogatni-szerbia-eu-csatlakozasatq0 - 01/10/2011.)

32 Glatz Ferenc (Ferenc Glac), "Történelmi megbékélés, de hogyan?” (Istorijsko pomirenje, ali kako?), História 1-2/2011, Budapest, 2011, pp. 2, 51-62 (autor je predsednik mađarske sekcije srpsko-mađarske akademijske mešovite komisije). 


\section{Summary}

József Juhász, Ph. D.

\section{Loyality to the West, Pragmatism Towards Serbia: Hungary's Foreign Policy Towards Serbia After the Regime Change}

Key words: Hungary, Serbia, Yugoslavia, foreign policy, international relations

The study analyzes Hungary's foreign policy towards Serbia from 1989 to early 2010. It argues that, regarding the basic principles, Hungary always preferred the development of Hungarian-Serbian relations. However, relations in the 1990s (unlike the good Hungarian-Yugoslav relations of the 1980s) were cold and tense because their atmosphere was defined by the discrepancy between the political orientation of the two countries ("westernisation" and Euro-Atlantic integration in Hungary versus the Milošević-era in Serbia). Inevitable conflicts resulted, but the political distance between the two countries, in some cases, was also increased by the politics of right-wing Hungarian governments (e.g. in the "Kalashnikov scandal"). Hungary's dual attitude towards Serbia characterized the whole decade of the 1990s. On the one hand, Hungary endeavored to have a pragmatic attitude, maintaining the "open doors" policy towards Serbia (if only for the 250 thousand Hungarians in Vojvodina). On the other hand, Hungary accepted the West's standpoint on Serbia because it wanted maintain its loyalty to the West due to its aspirations for integration into Euro-Atlantic organizations. At the end of 2010 a new period began in Hungarian-Serbian relations. The fall of the Miloševiæ regime removed the political discrepancies between the two countries and thereby new basis was created for establishing relations. This new period can already be qualified as successful: although some pronounced issues remain (especially relating to minorities), there are no serious conflicts between the two countries. 